\title{
Mechanically Stabilized Earth with Steel Reinforcement
}

\author{
Magdi M. E. Zumrawi ${ }^{1, *}$, Abubaker B. B. Barakat ${ }^{2}$, Idris M. I. Abdalla ${ }^{2}$ and Rabab A. A. Altayeb ${ }^{2}$ \\ 1 Deputy Dean for Academic Affairs, Faculty of Engineering, University of Khartoum \\ 2 M.Sc. student, Civil Engineering Department, Faculty of Engineering, University of Khartoum \\ * Corresponding author: Magdi M. E. Zumrawi (e-mail: magdi.zumrawi@yahoo.com).
}

Article history: Received 3 April 2020, Received in revised form 4 November 2020, Accepted 11 November 2020

\begin{abstract}
This paper presents the Mechanically Stabilized Earth (MSE) technique as a practical option for earth retaining wall structures. The literature pertaining soil reinforcement methods and their application in MSE walls were intensively reviewed. The present work focused on evaluating the performance of MSE walls with backfill soil reinforced by steel strips. Almolid square overpass bridge in Khartoum, which was constructed in 2015 with MSE walls as lateral support of the overpass ramps, was considered as case study. Based on field observations, the current status of the overpass bridge has proven that the use of MSE walls is successful and beneficial for sustainability of the overpass.
\end{abstract}

Keywords: Mechanically stabilized earth, Soil reinforcement, Steel strips, Backfill.

\section{INTRODUCTION}

Earth reinforcement technique is widely used in supporting earth structures. In fact, soils are weak in tension. Thus, compacted soils used as backfill material in retaining wall structures can be subjected to tensile failure. Therefore, to increase the tensile behavior of soils, some reinforcing elements are used to increase the strength and stiffness of the soil. Strengthening of soil by tensile elements such as metal rods or strips, fabrics (geotextiles) and geogrids improves the properties of the soil.

Mechanically stabilized earth (MSE) walls, also known as reinforced soil walls, are a special type of earth retaining structures, composed primarily of three elements: earth fill of granular soil, reinforcements which is typically made of metallic or geosynthetic material, and facing units. In fact, reinforced soil retaining walls can be considered as composite structures where the earth fill stability and capacity to retain backfill are improved by the reinforcements [1]. MSE walls have become an attractive alternative to traditional reinforced concrete retaining walls due to its simplicity, flexibility, and more economical. Even though MSE walls have been extensively used in many countries as lateral support of highway embankments or access ramps, they have not been well introduced in our country. Hence, it requires detail study to adopt this technology for locally available materials. This paper aims to evaluate the performance of MSE walls with backfill soil reinforced by steel strips.

\section{LITERATURE REVIEW}

\section{A. Soil Reinforcement}

The soil reinforcement technique is adopted to improve mechanical properties of soil such as stability, bearing capacity and reduce settlements and lateral deformations using materials like steel, stainless steel, aluminum, fiber glass, nylon, polyester, polyamides in the form of grids and geotextiles. The interaction between soil and the reinforcing member is solely by friction generated by gravity. A wide range of alternatives exists in making a choice of reinforcing materials. However for the selection of reinforcement, the load on the structure and its function as well as the cost should be considered while selecting the type of reinforcement [2]. Various types of reinforcing materials are described below. 
Reinforcing elements such as geotextiles or geogrids are widely used in retaining walls, slopes and embankments since they provide an economical and practical solution. Geotextile is used as soil reinforcement due to its resistance against the harsh soil conditions. Sometimes it is called synthetic fiber and it is made up from nylon, polyethylene, polyester, and polypropylene. The geotextile is available in forms of sheets, or strips to reinforce the soil [3]. The hydraulic conductivity of the geotextile is much higher than that of the surrounding soil, which makes the water run from the soil toward the geotextile. The geotextile installation process consists of removing about $1 \mathrm{~m}$ from the soil and spreading the geotextile and then backfilling the soil. Geotextile can also applied as strips to increase the shear strength of soil. In this case, vertical and horizontal spaces should be designed to insure best effect on the shear strength. The geo-grids can be used as a single layer or multilayers to improve the bearing capacity of soil. This technique is efficient enough to increase the bearing capacity of spread footing up to 2.5 times of the bearing capacity without reinforcement [4]. The selection of the geotextile and geo-grid materials should be preceded by laboratory tests to study the strength and the durability of the material [5]. Osman [6] used fiber-reinforced sand and geo-textiles sheets below isolated footings rest on soft clay. The results obtained showed that the settlement decreased and the bearing capacity increased. Al Mosawe et al. [7] present the results of geo-grid reinforcement installed below square footing rest on sandy soil and subjected to eccentric loading. The results show improvement in the bearing capacity ratio by ( $22 \%$ to $48 \%$ ) for one and two layers of geo-grid reinforcement.

Amongst the various types of reinforcement used in reinforced earth construction, bamboo strips have been used for long time. They are used both as strips and mats. But bamboo deteriorates quickly in wet conditions and is also prone to fungus and insect attacks as shown in Fig. 1. The bamboo reinforcements need elaborate preservative treatment before use. Bamboo, having mechanical and physical properties in comparison to geotextile or metals, can only be used in small or temporary works. Khan [8] investigated the effect of Bamboo industry waste on CBR and swelling of the treated soil. The results showed that using such material can improve the CBR value and reduce swelling with increasing fiber content.

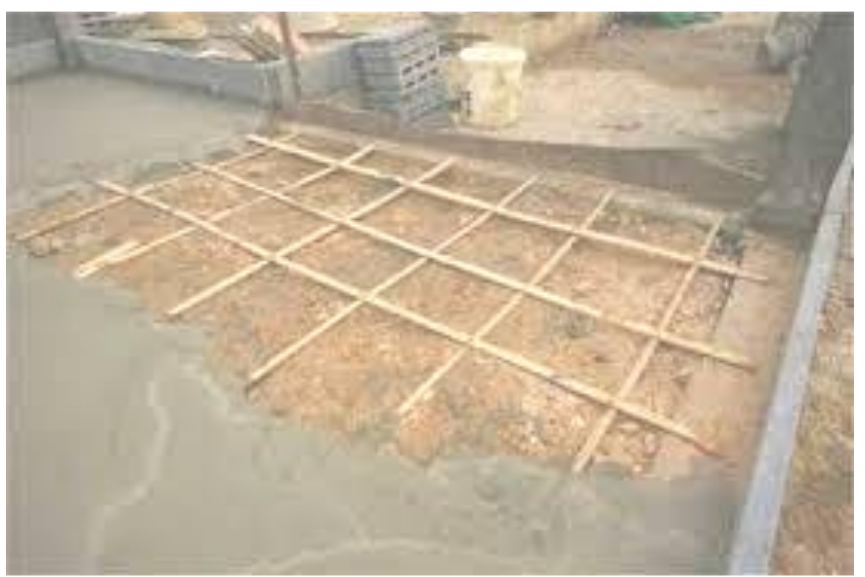

Fig. 1 Bamboo Strips used in earth construction [8]

The most commonly and extensively used reinforcement in earth reinforced structures is mild steel or high tensile bars and mats. The behaviour of reinforced soil is similar to reinforced concrete. Soil is weak in tension just like concrete. The addition of reinforcing strips or mats in the horizontal direction compensates for the weak tensile strength of soil. The steel reinforcement has excellent physical and mechanical properties. Reinforced soil retaining walls or reinforced earth walls are commonly grouped as Mechanically Stabilized Earth (MSE).

\section{B. Mechanically Stabilized Earth (MSE)}

Mechanically stabilized earth (MSE) walls are well-recognized alternatives to conventional retaining walls due to many advantages such as ease of construction, economy, and aesthetics. This is a structural system used throughout infrastructure for earth retention and load support. MSE systems are utilized to meet a variety of infrastructure needs, including highway retaining walls, bridge abutments, ramps, and overpasses as well as structures for railroads, mass transit, airports, and commercial and industrial facilities. Using a MSE wall as a bridge abutment has become an attractive option to the traditional cast-in place wall abutment. The use of an MSE wall abutment notably simplifies the design and construction of the bridge abutment, requires less site preparation, allows faster construction, and consequently leads to 
cost saving [9].

Mechanically Stabilized Earth (MSE) Technique is used as a practical solution. In this technique, the backfill soil acts as a retaining structure and facing units act as a supporting system. The facing units of first row are installed, which are made up of precast concrete panels, dry cast modular blocks, metal sheets and plates, gabions, welded wire mesh, wood lagging and panels, and wrapped sheets of geosynthetics. Then backfilling earth should be properly compacted and reinforced by means of reinforcing elements like steel strips or bars, welded wire mats, polymer grids or geotextile sheets. These reinforcing elements mechanically stabilize the earth [10].

Mechanically stabilized earth structures typically have three main elements, facing; reinforcement; and backfill as shown in Fig. 2. Facing is a vertical wall most commonly constructed of interlocking precast concrete panels with standard or custom-designed architectural finishes. In addition to its architectural features, facing prevents localized erosion and has embedded connectors for attaching the reinforcements. Reinforcements extend from the facing into the backfill for a distance related to wall height and structural loading, but at least $70 \%$ of the wall height. The reinforcements are flat, ribbed steel strips, welded wire mats, or bar mats, typically hot-dip galvanized after fabrication. Friction between reinforcements and backfill binds everything into a strong stable mass. Backfill is the soil which forms the bulk of the MSE structure. Backfill is placed in compacted layers, alternating with facing panels and reinforcements, until the structure's required height is reached. The stability of the wall system is derived from the interaction between the backfill and soil reinforcements, involving friction and tension. The wall facing is relatively thin, with the primary function of preventing erosion of the structural backfill. The result is a gravity structure that is flexible and can carry a variety of loads [9].

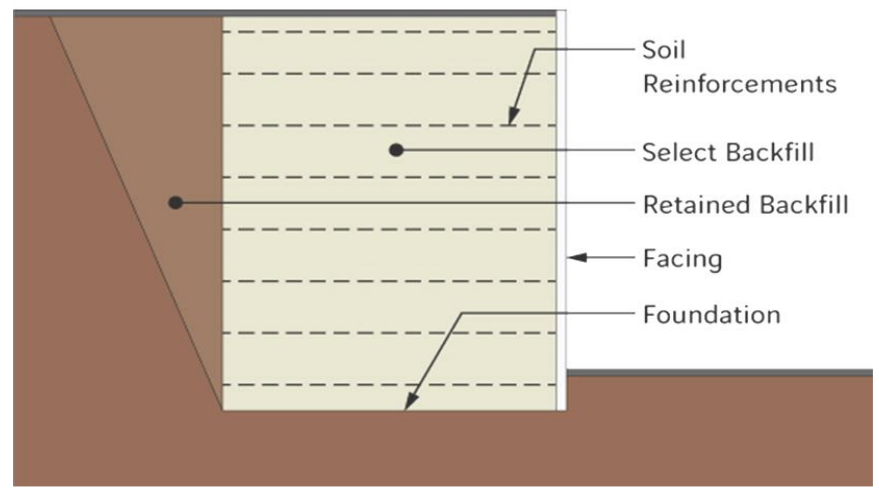

Fig. 2 Basic MSE Wall Components [9]

The type of MSE wall reinforcement and facing are selected on the basis of the MSE wall height, soil conditions, application type, and MSE wall height. The behavior of the backfill soils can greatly affect the performance of the MSE wall. MSE wall construction needs well-graded granular backfill materials that offer sufficient drainage, durability, and adequate soil reinforcement interaction. However, using backfill soil with a high fine content can cause poor drainage and significant movement of the MSE wall and may lead to failure [11].

MSE structure provides a number of benefits such as flexibility to accommodate high differential settlement, bearing pressure is distributed over a wide foundation area, extreme wall heights can be achieved, extreme loads can be carried, high resistance to dynamic forces, free-draining, due to granular backfill and open panel joints, form liners or elaborate murals can customize the aesthetics, soil reinforcing strips can easily accommodate obstructions within the MSE backfill volume, special design can allow for nearly any geometry, rapid, predictable, and repetitive construction.

The design procedures for the internal and external stability of an MSE wall are presented in design codes published by organizations such as AASHTO [12] and the British Standards Institution [13]. Construction of an MSE wall consists of setting several layers of reinforcement and dense soil in the back of a facing panel to form a composite material that behaves integrally to resist the lateral earth pressure. MSE walls are considered gravity walls that are flexible and can allow horizontal and vertical movements.

The use of an MSE wall as a bridge abutment has become a popular alternative to the conventional cast-in-place concrete wall 
abutment. Using an MSE wall provides a notable simplification to the design and construction of bridge abutments, requires less site preparation, leads to faster construction, and results in a cost saving. MSE walls are available with a broad range of potential facing types, colors, and textures, allowing owners and designers to build walls that fit into the aesthetics of the site conditions [14].

\section{CASE STUDY}

\section{A. Project Overview}

Almolid Square Overpass Bridge is constructed to carry the traffic of Hurria Street over Ahmed Khair Street at Alsaganah in Khartoum. The project is located in a very crowded area in Khartoum nearby the buildings of National Medical Supplies Fund as shown in Fig. 3. This project is part of a large infrastructure project in Khartoum to improve traffic congestion on major streets. The project is owned by the ministry of infrastructure of Khartoum state, Road and Bridges Cooperation.

The Overpass design was awarded to Alani and Alshama Consultant Company in 2013 and shortly thereafter preliminary construction began. The construction of the abutment with Mechanically Stabilized Earth (MSE) structures was completed in July 2015.

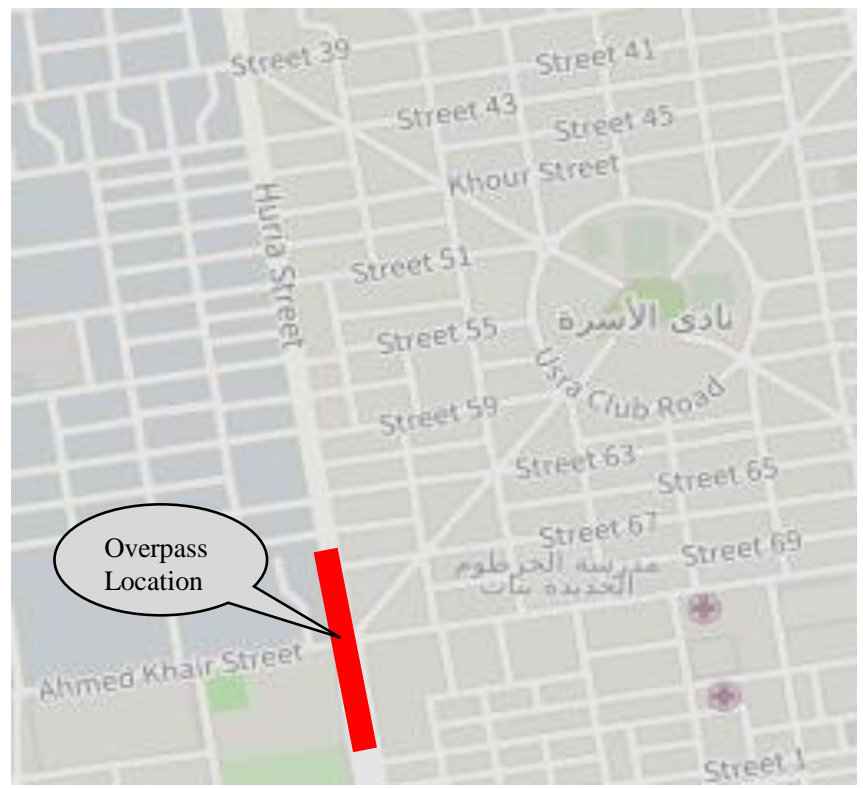

Fig. 3 Location of Almolid Square Overpass Bridge
This Overpass Bridge consists of eight spans, with total length of $300 \mathrm{~m}, 10 \mathrm{~m}$ width and $4.5 \mathrm{~m}$ height at the highest point. Foundation type adopted is piles and combined footings connected with square concrete columns with tie beams, and circular columns connected with concrete crosshead which contain pedestal with elastomeric bearing beds, with steel girders and deck slabs (See fig. 4).

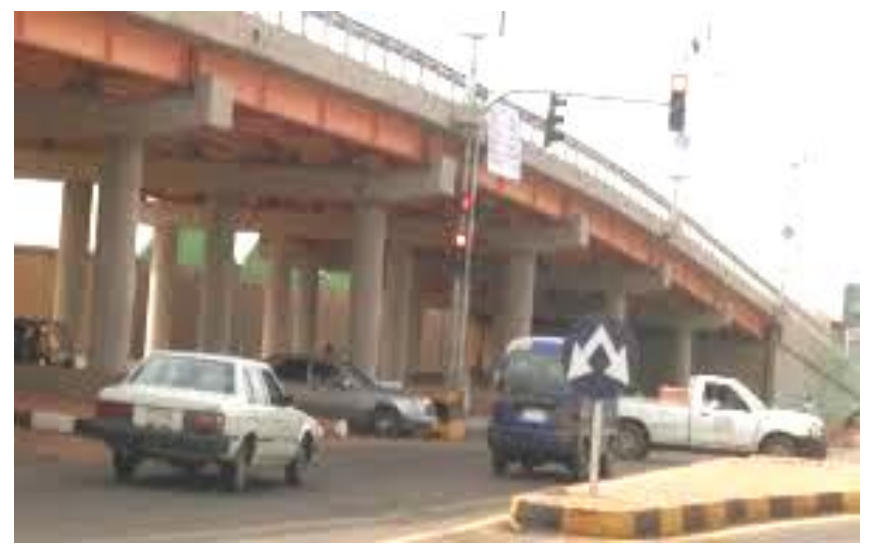

Fig. 4 Side view of Almolid Square Overpass Bridge

\section{B. Overpass Bridge Structure}

The structure of this overpass bridge forms of MSE Walls using precast concrete facing, steel strip reinforcement, and backfill soil. The MSE walls are used to stabilize what would otherwise be unstable slopes. They are a gravity structure in which reinforcement is placed horizontally in selected locations creating a frictional interaction between reinforcement and soil. Additionally, backfill is placed and compacted in specified lift sizes between the reinforcement; the reinforcement provides enough tensile resistance to stabilize the reinforced earth volume. A precast concrete panel is attached to the soil reinforcement and protects the structure from any loss of fill or compaction.

The soil reinforcement used for this structure is steel strips. The steel used is deformed galvanized strips of dimensions, $6 \mathrm{~m}$ and $4 \mathrm{~m}$ lengths; $45 \mathrm{~mm}$ width; $5 \mathrm{~mm}$ thick. The measured tensile strength of the steel is $510 \mathrm{MPa}$. The connection of the steel strip to the precast concrete facing is created by four bolts which are embedded into the concrete panel during casting to connect with the steel strip through edge holes (see Fig. 5). 


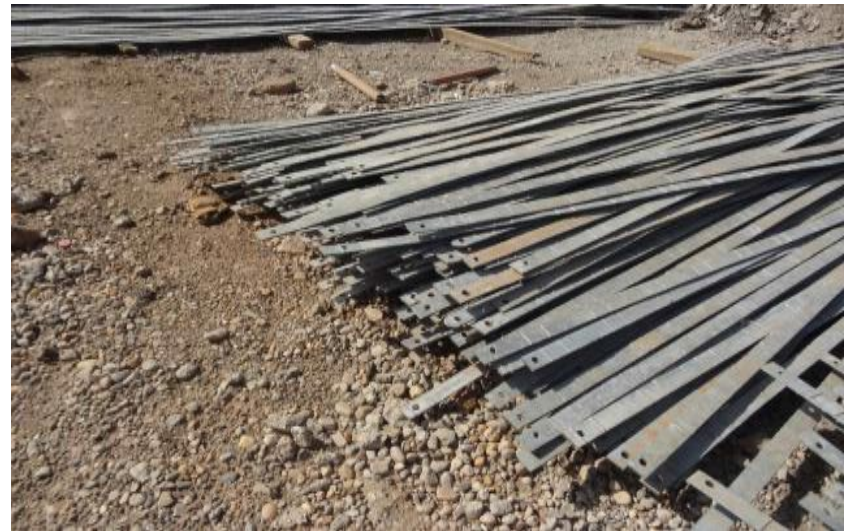

Fig. 5 Galvanized Steel Strips used as soil reinforcement

The type of facing element used in the construction of MSE walls is unreinforced precast concrete units. The facing panels are the only visible parts of the structure and therefore used for their aesthetics and provide protection against backfill sloughing and erosion. The MSE concrete panels were casted in-situ (see Fig. 6). The precast concrete panels have a thickness of $150 \mathrm{~mm}$ and of a geometric shape as shown in Fig. 7.

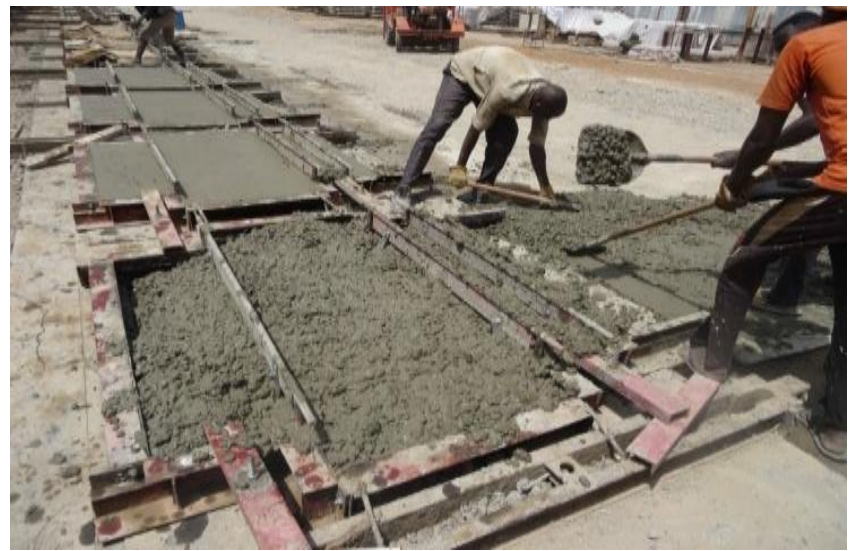

Fig. 6 The MSE Panels casted in site

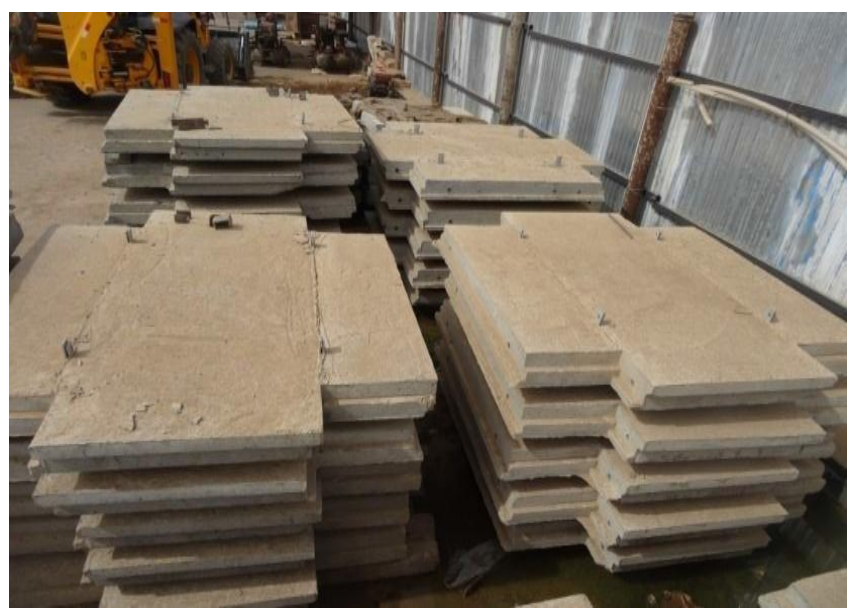

Fig. 7 The fencing precast concrete units
The backfill soil used in MSE structure is granular material (see Fig. 8). The soil physical and mechanical properties such as gradation, plasticity, compaction and strength parameters were measured in the laboratory. The backfill soil used is classified as clayey Sand (SC) of low plasticity and fine content $(\mathrm{PI}=12 \%$, percent passing no. 200 sieve $=20 \%$ ), optimum moisture content $7.5 \%$ and maximum dry density 2.21 $\mathrm{g} / \mathrm{cm}^{3}$ and moderate strength $(\mathrm{CBR}=35 \%)$.

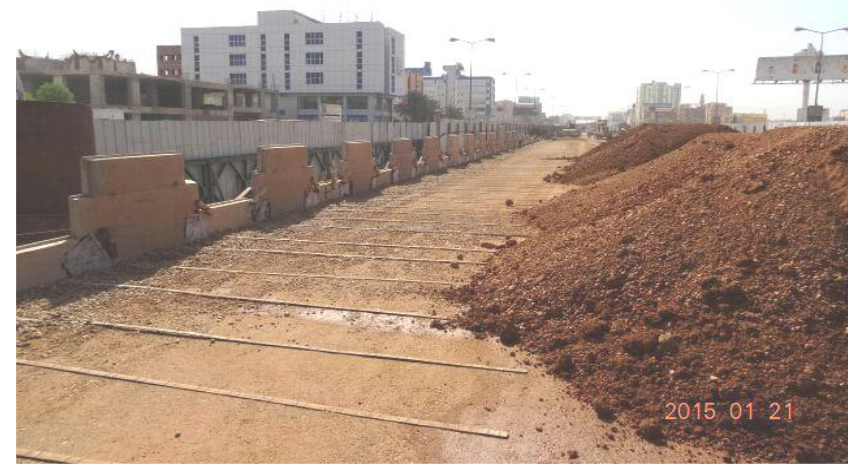

Fig. 8 The backfill material used in construction of MSE

\section{Construction process}

Building the project Overpass MSE walls took place in May 2013 and completed in July 2015. The construction process for building the MSE walls was applied, and is typical to standard MSE construction; which consist of:

o Excavate/prepare the site and foundation

o Pour unreinforced concrete levelling pad

- Install and brace first course of panels

- Backfill and compact at lifts

- Continue with placement of concrete panels.

The site was prepared and the weak soil was removed from the ground surface. At the facing location, concrete leveling pad have dimensions $150 \mathrm{~mm}$ thick and $300 \mathrm{~mm}$ wide was placed at the correct elevation. An improperly placed leveling pad can result in subsequent panel misalignment and cracking as well as the top of the wall will not be at the correct elevation. The first row of precast concrete facing panels was set directly on the concrete leveling pad as shown in Fig. 9. Adjacent panels were clamped together to prevent individual panel displacement. Precast facing panels were set to correct vertical alignment. 


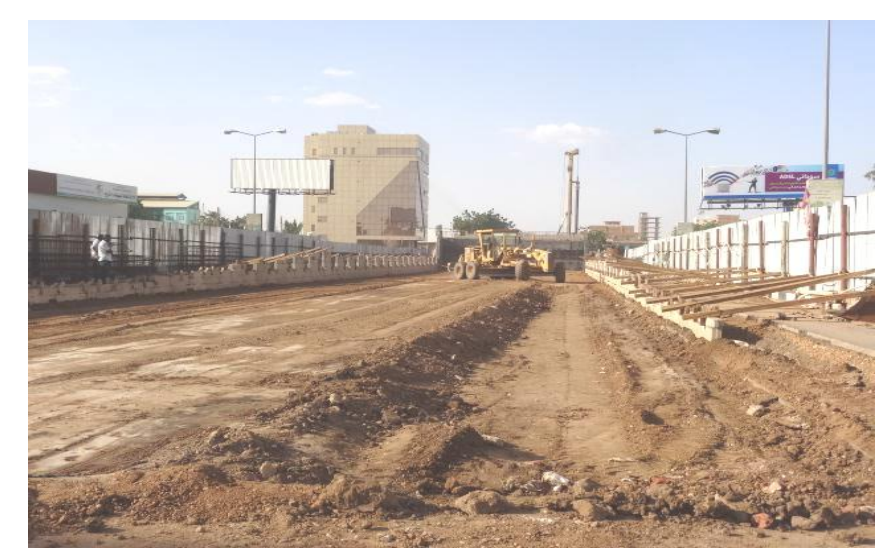

Fig. 9 Setting of the first row of precast facing panels

The first layer of backfill soil was laid down with $20 \mathrm{~cm}$ thickness and compacted at optimum moisture content and maximum dry density. The compaction was tested to make sure that it satisfied the requirements. The steel strips were then placed on compacted soil at a horizontal and vertical spacing of $1 \mathrm{~m}$ (see Fig. 10). The strips were tied with the MSE walls by bolts on compacted soil layer and this step was repeated until the top design level was reached of the embankment.

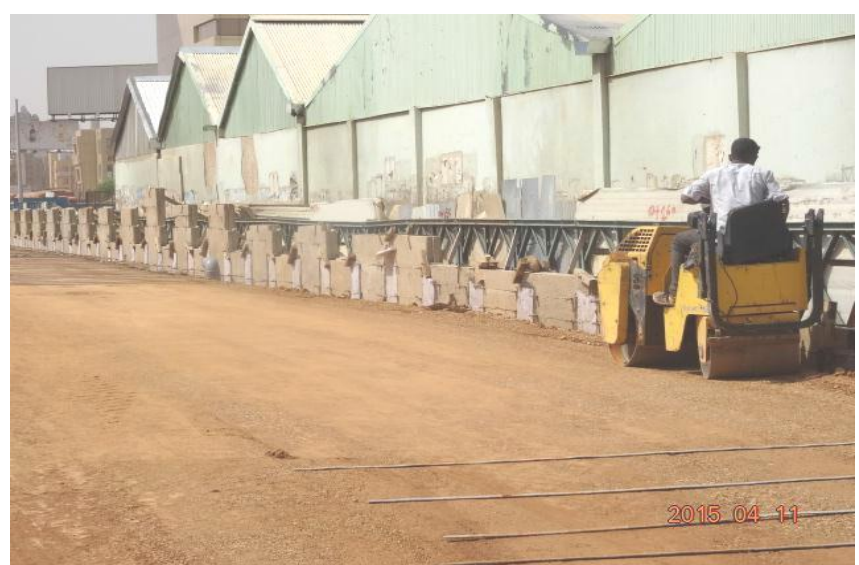

Fig. 10 Compaction by rolling of reinforced backfill soil

\section{Current Status}

Visual field inspection of the MSE walls was conducted in Oct. 2019 to evaluate the current status of Almolid square overpass bridge after construction completed in July 2015. The field observations as outlined below.

Facing/panels: MSE wall facing of precast concrete panels. They are considered the aesthetic element of the MSE wall. Facing provides protection against erosion and protects and confines the fill material. They are in new condition, no damage and no rust staining noticed.
Panel joints: the spaces between adjacent panels are in good condition and consistent joint width seen throughout the wall. No leaking of backfill soil was observed.

Coping/top of the wall: The coping used to tie in the top of the wall panels and finish the top of the wall. It was observed that no sign of cracking or deterioration occurred in the coping and the top of the wall.

The wall (back and toe): there is no indication of erosion and scour of the soil at the back and the toe of the MSE walls observed. The walls appear with no change in tilting from construction specifications.

The results of the field inspection of Almolid square overpass bridge after four years from construction completion date showed that the MSE walls are in good condition and no repair or immediate action is needed. This result clearly demonstrates that the MSE walls are reliable and efficient option as retaining earth structures if they are properly designed and constructed.

\section{CONCLUSION}

This paper discusses the use of soil reinforcement technique in construction of mechanically stabilized earth walls for bridge abutments, access ramps and overpass structures. The study findings showed that the use of a mechanically stabilized earth (MSE) wall greatly simplifies the design and construction of the retaining walls, requires less site preparation, allows faster construction, and consequently leads to cost saving. The good performance and durability of an MSE wall may be related to proper design and construction.

\section{REFERENCES}

[1] T. S. Ingold, Reinforced Earth, Thomas Telford Ltd, 1982.

[2] M. Asaduzzaman and M. I. Islam, "Soil Improvement By Using Bamboo Reinforcement," American Journal of Engineering Research (AJER). Vol. 3, Issue 8, pp 362-368, 2014.

[3] L. E. Bowles, Foundation analysis and design. McGraw-hill, 1996.

[4] M. Gunaratne, The foundation engineering handbook. CRC Press, 2013.

[5] P. C. Varghese, Foundation engineering. PHI Learning Pvt. Ltd, 2005.

[6] E. A. M. Osman, "Reinforced Earth Mat Foundation over Fiber-Reinforced Sand Columns inside soft Clay", J. of Nepal Geological Society, Vol. 32, pp 16-24, 2005. 
[7] M. J. Al Mosawe, A. A. Al Saidi, and F. W. Jawad, "Bearing Capacity of Square Footing on Geogrid Reinforced Loose Sand to Resist Eccentric Load", Journal of Engineering, No.2, Vol. 16, pp 4990-4999, 2010.

[8] S. A. Khan, "Stabilization of Soil Using Bamboo Industry Waste", 32:18-19 July, Coimbra, Portugal, pp 357-362, 2005.

[9] R. R. Berg, P. E. Barry, R. Christopher, Design and Construction of Mechanically Stabilized Earth Walls and Reinforced Soil Slopes - Volume II, U. S. Department of Transportation Federal Highway Administration, Report No. FHWA-NHI-10-025 FHWA GEC 011-Vol II, November 2009.

[10] H. D. Golakiya and M. D. Lad, "Design and Behaviour of Mechanically Stabilized Earth Wall", International Journal of Emerging Technologies and Innovative Research (JETIR), Vol.2, Issue 11, pp145-153, November-2015.

[11] M. S. Hossain, G. Kibria, M. S. Khan, J. Hossain, and T. Taufiq, "Effects of backfill soil on excessive movement of MSE wall," J. Perform. Constr. Facil., (ASCE), 26(6), 793-802, 2012

[12] AASHTO. LRFD bridge design specifications, $5^{\text {th }}$ Ed., Washington, DC, 2010

[13] British Standards Institution, Code of practice for strengthened/ reinforced soil and other fills. BS 8006, Milton Keynes, U.K., 2010

[14] D. E. Alzamora, and S. A. Anderson, "Review of mechanically stabilized earth wall performance issues." Proc., $88^{\text {th }}$ Annual Meeting (CD-ROM), Transportation Research Board, Washington, DC, 1-16, 2009.

Dr. Magdi Zumrawi was born in Omdurman, Sudan, 19 May 1963. He received the B.Sc. degree in Civil Engineering and M.Sc. degree in Road Technology from University of Khartoum in 1987 and 1991, respectively. He achieved Ph.D. in Highway and Railway Engineering in Sept. 2000, Chang'An University, Xi'an, China. Now he is Associate Professor in Highway Engineering. His present occupation is Deputy Dean for Academic Affairs, Faculty of Eng., Khartoum University, since Dec. 2019. He is a highway expert working with local and international consultant firms. He has published many articles in local and international journals and attended national and international conferences. He is a member of International Society for Soil Mechanics and Geotechnical Engineering. He is a senior member of the APCBEES. 